\title{
Predicting Performance of Briquette Made from Millet Bran: A Neural Network Approach
}

\author{
Gaurav Kumar ${ }^{1 *}$, Gireeshkumaran Thampi B.S. ${ }^{1}$, Pranab Kumar Mondal ${ }^{2 *}$ \\ ${ }^{1}$ Department of Mechanical Engineering, School of Engineering, Cochin University of Science and \\ Technology, Kochi, Kerala, India - 682022 \\ ${ }^{2}$ Department of Mechanical Engineering, Indian Institute of Technology Guwahati, Assam, India - 781039
}

* Corresponding Authors email: me.gaurav@cusat.ac.in mail2pranab@gmail.com

Article Histary

Received: 01 June 2020

Revised: 18 August 2020

Accepted: 06 September 2020

Published: 21 September 2020

Student(s)

- Gaurav Kumar

$$
\begin{aligned}
& \text { Academic Year: 2019-20 } \\
& \text { Course Level: Bachelor } \\
& \text { Course Name: B.Tech. }
\end{aligned}
$$

(Mechanical Engineering)

Course year: $4^{\text {th }}$ Year $/ 8^{\text {th }}$ Semester

Mentor(s)

- $\quad$ Dr. Gireeshkumaran Thampi B.S.

- Dr. Pranab Kumar Mondal

\section{ABSTRACT}

Millet bran possesses good fuel quality and can be successfully used as a professional feedstock for producing solid biofuel. In this paper, a framework for developing an Artificial Neural Network (ANN) to estimate the performance of millet bran briquettes is presented by using experimental data to train, test, and validate the ANN. With the capacity of the developed multi-layer ANN, the effects of moisture content, temperature, and applied pressure on the density, durability, and impact resistance are predicted. Different cases considering three parameters as inputs to the ANN, namely, moisture content, temperature, and applied pressure were analyzed. The outputs of the ANN are the density, durability, and impact resistance for each of the input parameters separately. By comparing with the experimental values, it is shown that the ANN-based method can predict the data well with a Mean Square Error (MSE) value $\sim 0.2 \%$. Further, Multiple Linear Regression (MLR) model is used to check the efficiency of ANN prediction from which it is shown that the proposed ANN-based method provides useful guidance for the prediction of the physical parameters efficiently, with the least deviation and high accuracy.

Keywords: Biomass, Millet bran, Briquette, Artificial Neural Network, Multiple Linear Regression.

\section{Introduction}

Nearly up to three billion people worldwide cook using fuel wood daily [1]. In the search for an alternative source of energy, biomass is considered as an important renewable energy source because of its appealing properties, such as lower production cost, less greenhouse, and acidic gas emissions. The conversion of energy from the biomass does not demand a unique process to be executed; instead, several processes are available for this underlying conversion [2]. Examples include direct combustion, gasification, pyrolysis, anaerobic digestion, hydrolysis, hydrogenation, and fermentation. This aspect brings intense interest among the researchers to interrogate several aspects of the biomass energy conversion systematically. An overview of the available technologies to produce heat, electricity, or other products like 
ethanol composites, absorbents from rice husks, and rice straw has been well documented in the reported review [3]. It may be mentioned in this context here that briquettes have gained huge popularity to the community, attributed primarily to their advantages over the traditional cooking means of charcoal and firewood [4]. Albeit a closer inspection of the pertinent literature largely vouches for the documentary proof of the uses and development of briquettes as well as the briquetting technology [5], several pieces of research focusing on the different aspects of biomass briquettes have been conducted as well [6-8]. Mani et al. determined the mechanical properties of wheat straw, barley straw, corn stover and swtichgrass by the application of compressive forces, particle size and moisture contents [6]. Kaliyan $e t$ al. helped to determine the important process parameters to produce strong and durable biomass pellets, briquettes and cubes. The strength was determined by parameters such as compressive resistance, impact resistance, and water resistance [7].

In India, the average waste millet straw generated every year ranges in tons, and most of the straws are either abandoned in the field or burnt away [9]. Biomass densification into briquettes results in an increase of energy density and minimizes particulate emission per unit volume of fuel transported and, at times, improves the combustion efficiency [1,10,11]. Muazu et al. provided the study on blending of different types of biomass. This helped to improve the properties such as compressive strength, durability and mass loss due to impact of densified biomass briquettes [10]. Properties such as ash content, heating value, and physical properties (e.g., durability or impact resistance, density, and compressive strength) affect the combustion and handling issue of the biomass briquettes [12]. Ash content and heating value are feedstock dependent, whereas durability, impact resistance, density, and compressive strength depend on the briquetting conditions. The quality of briquettes made is also dependent on several parameters like density, drop resistance, calorific value, and resistance to water absorption [13,14]. Yank et al. used rice husks to make briquettes and the physical properties (density, moisture content, calorific value, durability, and compressive strength) were tested to identify the briquettes with the highest quality [1]. From the preceding discussion, it is easily perceptible a complex and non-linear relationship among the input parameters, which, in turn, necessitating an expensive computational approach or statistical method to predict the performance of millet bran briquettes. Application of the ANN approach to predict the performance in various processes of biomass energy conversion could be an interesting proposition, primarily attributed to its high accuracy.

In recent years, artificial neural network (ANN) has emerged as an efficient, quick and accurate problem-solving method because of its ability to establish complex relationships between input and output values without any physical relation and system non-linearity. At the same time, a multi-layer feed-forward neural network has become an alternative to present the statistical techniques for data fitting and functional approximations $[15,16]$. The use of artificial neural network (ANN) in the field of mechanical engineering is being considered from the last decade, and its applicability is getting gradually increasing prominence as well. It is important to mention here that ANN is becoming quite popular in the field of thermal engineering [17-20], albeit remaining sparsely explored in the paradigm of renewable energy systems [21]. In this study, ANN as an approach is used to predict the physical conditions such as density, durability, and impact resistance, which are influenced by the parameters viz., the moisture content, temperature, and applied pressure of millet bran briquettes. A limited study on the prediction of the performance of briquettes made from millet bran is the motivation behind this study.

\section{Artificial Neural Network}

Artificial Neural Network (ANN) is a non-linear data processing device, which is built from interconnected processing units known as neurons and illustrated in Fig. 1. Neurons are the units that handle the computation in an ANN model (Fig. 2). They are interconnected and operate in parallel. The ANN model is data-driven and where it learns from the data (example), where input and output are fed to the model. The input and output layers are connected with neurons in which the hidden layer falls in between the layers. Each connection carries weight, and it is multiplied by the input. 


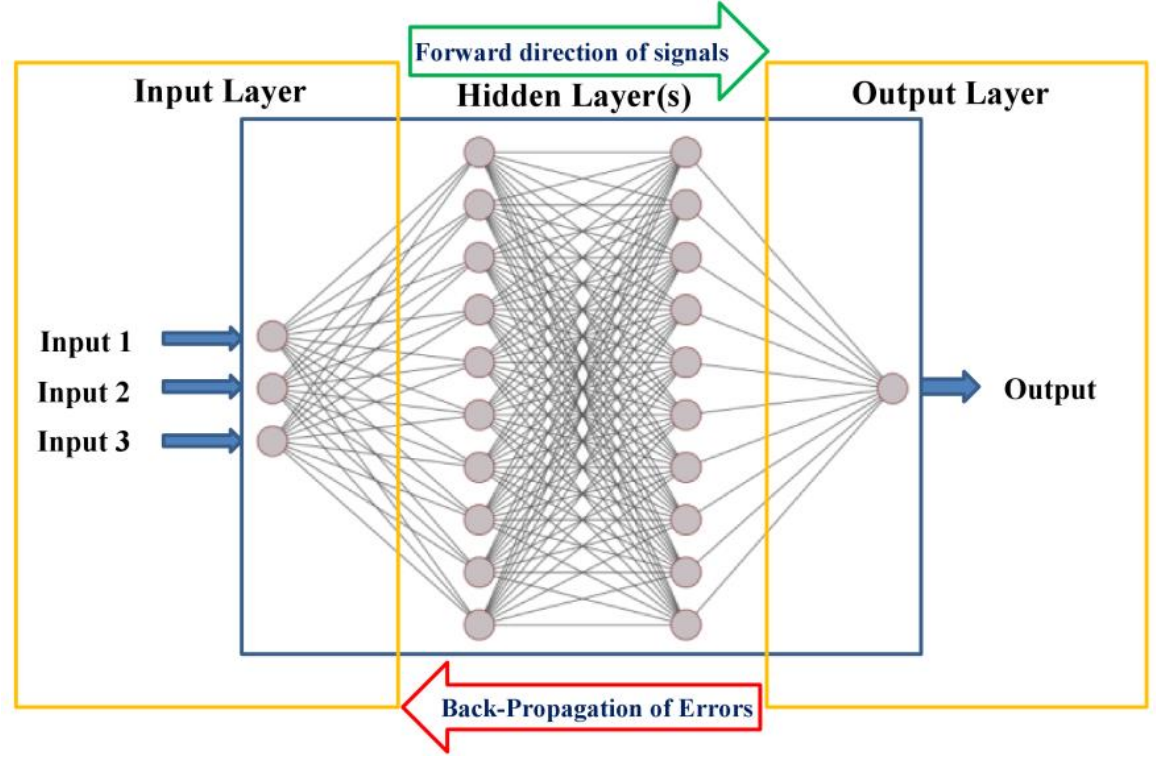

Figure 1: ANN diagram representing 3-10-10-1 structure

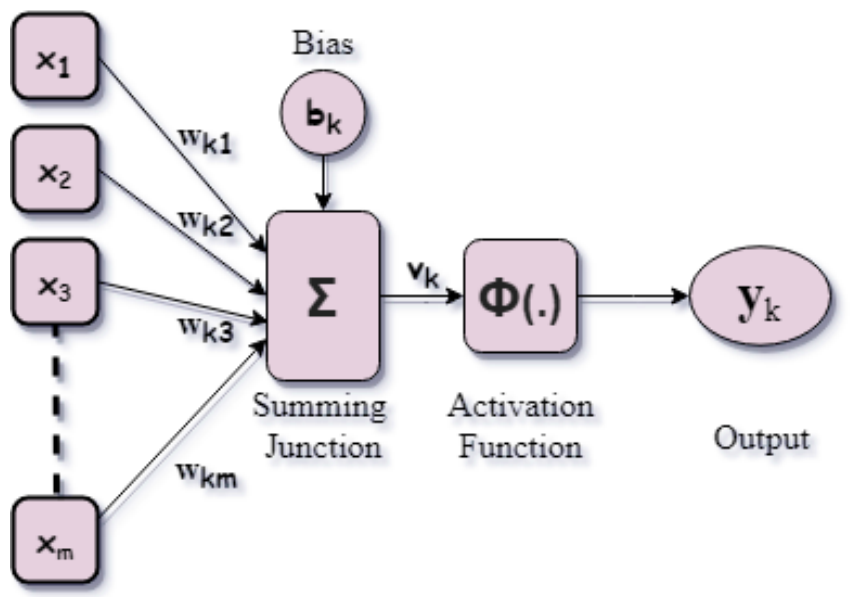

Figure 2: An artificial neuron containing elements like weights, bias, connections, and functions

This product and external bias is added and passes through the transfer function, also known as activation function consisting of algebraic equations. Every 'connection' between a node in one layer to the node of next layer has a 'weight'. It can be of positive or negative value and represents how strongly the source node influences any particular node to which it is connected. Next, a 'bias' value which can be either positive or negative is assigned to every node in the next layer. This allows further improvement in that node's value. The weight and bias are selected randomly, or it can be predefined. Activation functions (Transfer functions) are non-linear transformation that is performed over input signals. The transformed output is then sent to the next layer of neurons as input. There are various activation functions available such as linear, sigmoid, hyperbolic tangent, etc. out of which sigmoid is the most commonly used transfer function (Eq. 1) [22]. The transfer function captures the non-linear relationship between the inputs and converts them into more useful output [19].

$$
f(x)=\frac{1}{1+e^{-x}}
$$

Mathematically, a neuron can be described by writing Eq. 2, where $x_{1}, x_{2}, \ldots x_{m}$ are the input signal; $w_{k 1}, w_{k 2}, \ldots w_{k m}$ are the synaptic weights of the neuron $k ; u_{k}$ is the linear combination output due to input signals; $b_{k}$ is the bias; $\Phi($.$) is the activation function; y_{k}$ is the output signal of the neuron [23]. 


$$
\begin{aligned}
& u_{k}=\sum_{j=1}^{m} w_{k j} x_{j} \\
& y_{k}=\Phi\left(u_{k}+b_{k}\right)
\end{aligned}
$$

The ANN process consists of training, testing, and validation. There are several algorithms available for training neural network models, and the most popular among them is the backpropagation (BP) algorithm. In this technique, the neural network learns by altering the connection weights. The BP algorithm has three methods, which are Pola-Ribiere conjugate gradient (CGP), scaled conjugate gradient (SCG), and the widely used is Levenberg-Marguardt (LM) [24,25]. The LM method is most stable and efficient but consumes more significant memory to process the data. Levenberg-Marguardt (LM) algorithm is used because of fast convergence and stability while training the ANN [26]. Several studies using ANN of variable characteristics have been applied previously in the field of biomass for the prediction of properties such as the use of Support Vector Machine (SVM) [27,28], Radial Bais Function (RBF) [29,30], Adaptive Neuro [31,32], and Artificial Neural Network [33].

\section{Problem Statement}

In this analysis, for predicting the physical conditions of the millet bran briquettes, namely density $(\rho)$, durability $(\delta)$, impact resistance $(\eta)$, the effects of three influencing parameters which are moisture content $(m c)$, temperature $(T)$ and applied pressure $\left(P_{a}\right)$ have been considered $[7-8,10]$. The network aims to predict the physical conditions (density $(\rho)$, durability $(\delta)$, impact resistance $(\eta)$ ) using data of three influencing parameters (as input variables), which are $m c, T$ and $P_{a}$. The task is performed by MATLAB ${ }^{\circledR}$ using neural networks toolbox (version 9.60.1072779, 2019a The MathWorks Inc., USA). In general, structure, a single hidden layer, is considered in major applications [34,35]; however, the optimum number of hidden layers, as well as neurons, is problem-dependent and depends on many factors. A few factors include input complexity, mapping of output, noise in data, and the number of data points available. A double hidden layer structure for the training has been used with the number of neurons as 10 [31], and the network looked like, as shown in Figure 1. In this study, twenty-three experimental data points are taken from J. Zhang et al. [8] for ANN analysis. The main aim of the study is to show how ANN can be implemented to small number of experimental data set and bring a better statistical prediction as compared to other methods (such as regression). Out of the twenty-three data points, sixteen data points were randomly selected for training purposes and the remaining seven data points for testing and validation purpose. Important to mention here, the ANN model was devised using measured (experimental) data and to get a better prediction, different number of ANN structures where used and the one with highest accuracy is reported. Also in the end, the accuracy of our ANN model with statistical modelling method such as multiple linear regression (MLR) has been compared.

\subsection{ANN Modelling}

In this work, the four-layer structure $3-h-b-1$ is used where $b$ is the number of neurons in the hidden layer. The value of $b$ is varied from 1 to 12 and the most suitable structure is reported in present analysis. Hyperbolic tangent (tansig) is chosen as the transfer function for the hidden layer, and the linear transfer function (purelin) is chosen for the output layer. For each training, three input variables $\left(m c, T\right.$ and $\left.P_{a}\right)$ and one output variable is taken. In the first run, $\operatorname{density}(\rho)$ is taken as an output variable followed by durability $(\delta)$ and impact resistance $(\eta)$ in the successive runs. All the output variables (density, durability, impact resistance) are independent from each other in physical regard [8]. Because of it, while modelling ANN, all the variables are taken separately and not in a single model (3-x-x-3). This task is continued until the minimization of the error function during the training is achieved by altering the values of weights and 
biases of the network. In the present analysis, mean square error (MSE), mean absolute error (MAE), and mean bias error (MBE) is used as the error functions, which gives the measure of different errors between outputs of the network $(o)$ and target (experimental values) outputs, $(t)$ as shown in Eq. 3, Eq. 4, and Eq. 5 respectively.

$$
\begin{gathered}
M S E=\frac{1}{N} \sum_{i=1}^{N}\left(t_{i}-o_{i}\right)^{2} \\
M A E=\frac{1}{N} \sum_{i=1}^{N}\left|t_{i}-o_{i}\right| \\
M B E=\frac{1}{N} \sum_{i=1}^{N}\left(t_{i}-o_{i}\right)
\end{gathered}
$$

Another important indicator to declare the performance of the network is the correlation coefficient $(R)$ between target and predicted outputs. The value of $R$ lies between 0 and +1 , where the values close to +1 indicates a positive linear correlation and values close to 0 indicates a weak correlation $[36,37]$. The complete process of the ANN approach is summarized in the flowchart and given in Figure 3 for the sake of comprehensiveness in the understanding of the readers.

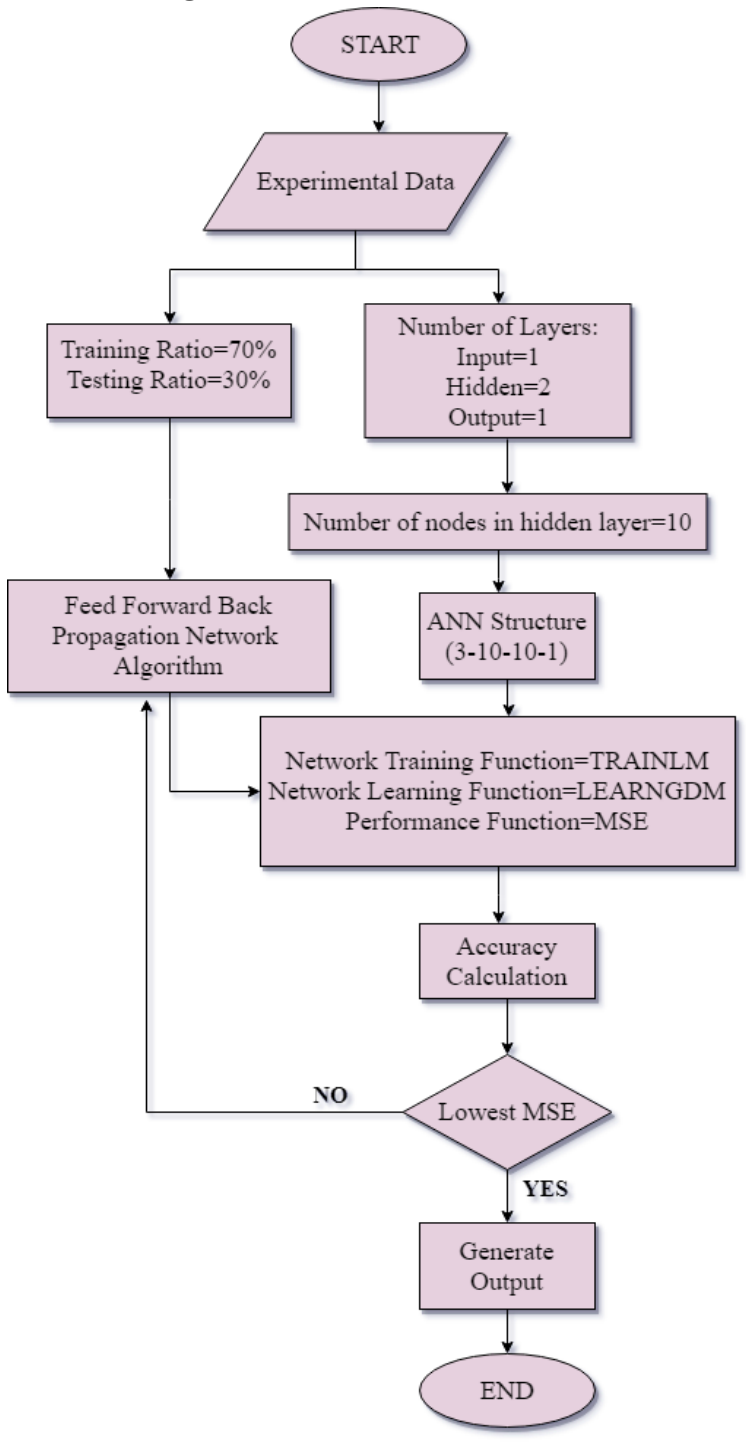

Figure 3: Flowchart of ANN program for the present analysis 


\subsection{MLR Modelling}

Multiple linear regression (MLR) is a traditional statistical technique to formulate complex input-output relationships [38]. The key aim of the MLR is to search out for an approximate linear function between a set of independent variables $\left(m c, T\right.$ and $\left.P_{a}\right)$ and the dependent variable (density $(\rho)$, durability $(\delta)$, impact resistance $(\eta)$ taken separately for each case). The regression line in MLR can be written as shown in Eq. 6:

$$
y=\beta_{0}+\beta_{1} x_{1}+\ldots \ldots+\beta_{k} x_{k}+\varepsilon
$$

where, $y$ is dependent variable, $x_{k}$ is the $k$-th independent variable, $\beta_{k}$ is polynomial coefficients of $x_{k}$, $k$ is the number of independent variables, and $\varepsilon$ is possible variation form.

\section{Results and Discussion}

Demonstration of the results is done in Table 1 for the proposed ANN model, and the parameters selected to train the neural network are shown in Table 2.

Table 1: Comparison of ANN results with the experimental data taken from J. Zhang et al. [8]

\begin{tabular}{|c|c|c|c|c|c|c|c|c|c|}
\hline & & & \multicolumn{3}{|c|}{ Density } & \multicolumn{2}{c|}{ Durability\% } & \multicolumn{2}{c|}{ Impact Resistance\% } \\
\hline Sl. No. & $m c$ & $T$ & $P_{a}$ & Experimental & ANN & Experimental & ANN & Experimental & ANN \\
\hline 1 & 8 & 90 & 130 & 1.01 & 1.01 & 90.46 & 82.79 & 96.72 & 96.70 \\
\hline 2 & 8 & 90 & 130 & 1 & 1.01 & 87.91 & 82.79 & 94.9 & 96.70 \\
\hline 3 & 8 & 90 & 130 & 1.1 & 1.01 & 89.71 & 82.79 & 98.52 & 96.70 \\
\hline 4 & 8 & 90 & 130 & 0.92 & 1.01 & 62.95 & 82.79 & 98.57 & 96.70 \\
\hline 5 & 8 & 90 & 130 & 0.98 & 1.01 & 80.95 & 82.79 & 94.9 & 96.70 \\
\hline 6 & 8 & 90 & 130 & 1.02 & 1.01 & 85.92 & 82.79 & 97.48 & 96.70 \\
\hline 7 & 8 & 90 & 130 & 1.03 & 1.01 & 85.51 & 82.79 & 95.75 & 96.70 \\
\hline 8 & 8 & 90 & 130 & 1.05 & 1.01 & 88.83 & 82.79 & 97.83 & 96.70 \\
\hline 9 & 8 & 90 & 130 & 1 & 1.01 & 86.24 & 82.79 & 95.82 & 96.70 \\
\hline 10 & 6 & 80 & 120 & 0.98 & 0.92 & 82.4 & 76.22 & 97.64 & 95.76 \\
\hline 11 & 6 & 80 & 140 & 0.93 & 0.93 & 64.62 & 62.95 & 97.1 & 96.23 \\
\hline 12 & 6 & 100 & 120 & 1.13 & 1.13 & 87.55 & 103.76 & 99.19 & 99.10 \\
\hline 13 & 6 & 100 & 140 & 0.95 & 0.95 & 79.95 & 85.42 & 94.8 & 95.04 \\
\hline 14 & 10 & 80 & 120 & 0.89 & 0.89 & 63.48 & 68.18 & 89.27 & 89.84 \\
\hline 15 & 10 & 80 & 140 & 0.91 & 0.91 & 67.52 & 84.50 & 97.44 & 95.93 \\
\hline 16 & 10 & 100 & 120 & 1.04 & 1.04 & 85.07 & 85.92 & 98.09 & 97.85 \\
\hline 17 & 10 & 100 & 140 & 0.91 & 0.94 & 61.61 & 62.14 & 98.03 & 98.25 \\
\hline 18 & 4.6 & 90 & 130 & 1.06 & 1.06 & 90.33 & 88.66 & 97.34 & 97.27 \\
\hline 19 & 11.4 & 90 & 130 & 0.9 & 0.90 & 67.48 & 67.45 & 95.4 & 95.10 \\
\hline 20 & 8 & 73 & 130 & 0.92 & 0.92 & 76.3 & 71.78 & 95.36 & 95.82 \\
\hline 21 & 8 & 107 & 130 & 1.09 & 1.02 & 92.99 & 91.36 & 98.38 & 98.29 \\
\hline 22 & 8 & 90 & 113 & 0.92 & 0.92 & 68.93 & 72.48 & 94.12 & 93.57 \\
\hline 23 & 8 & 90 & 147 & 1.02 & 1.02 & 84.48 & 81.80 & 95.7 & 95.69 \\
\hline
\end{tabular}


Table 2: Training parameters used for the ANN model

\begin{tabular}{|c|c|}
\hline Training Parameter & Value \\
\hline Training Function & TRAINLM \\
\hline Learning Function & LEARNGDM \\
\hline Performance Function & MSE \\
\hline Transfer Function & TANSIG, PURELIN \\
\hline epochs & 10000 \\
\hline min_grad & $1 \mathrm{e}-07$ \\
\hline mu & 0.001 \\
\hline max_fail & 60 \\
\hline
\end{tabular}

The total Epochs considered here are 10,000. Epoch states the single presentation of each input and output data on the training set, which presents the iteration at which the validation performance reaches a minimum [23]. At $b=10$, which is the structure, '3-10-10-1' has been used to predict each physical condition, and discussed in the following sections:

\subsection{Prediction of Density $(\rho)$}

ANN structure with input variables $\left(m c, T\right.$ and $\left.P_{a}\right)$ are taken in the input layer, and density $(\rho)$ is taken in the output layer. Relevant to mention here, a total of twenty-three data points was fed into the network and trained until the lowest value of MSE is obtained. After training, testing, and validating, it is found that $82.6 \%$ of the predicted data are within the error range of $\pm 5 \%$ as shown in Figure $4($ a). This prediction occurred at epoch 4 with mean square error (MSE) as 0.0022096. The best performance is obtained as epoch 4 because of the occurrence of the lowest value of MSE on the validating sets Figure 10(a). Later, in Fig. 4(b)., the comparison of the prediction made by ANN and MLR is shown. If the same error range of $\pm 5 \%$ is taken for MLR, it can be noted that $69.57 \%$ of data is predicted with standard error of 0.05603 .

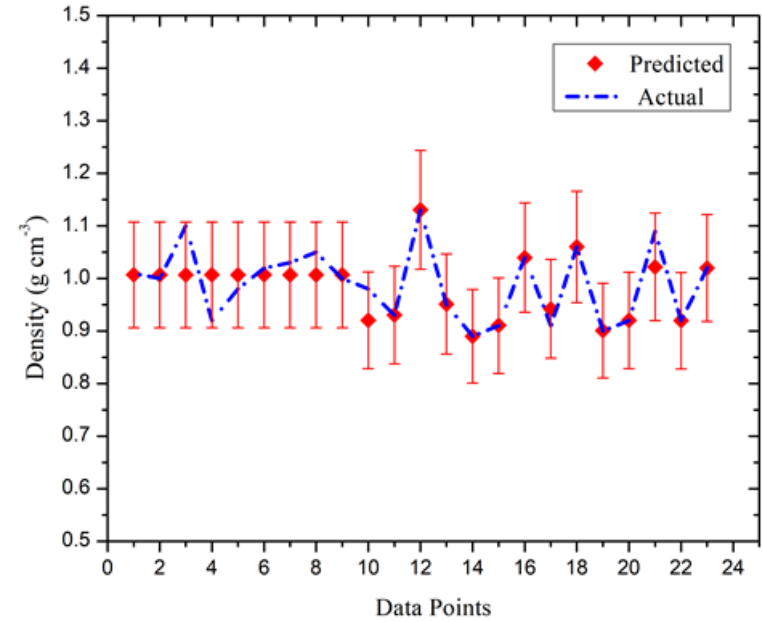

(a)

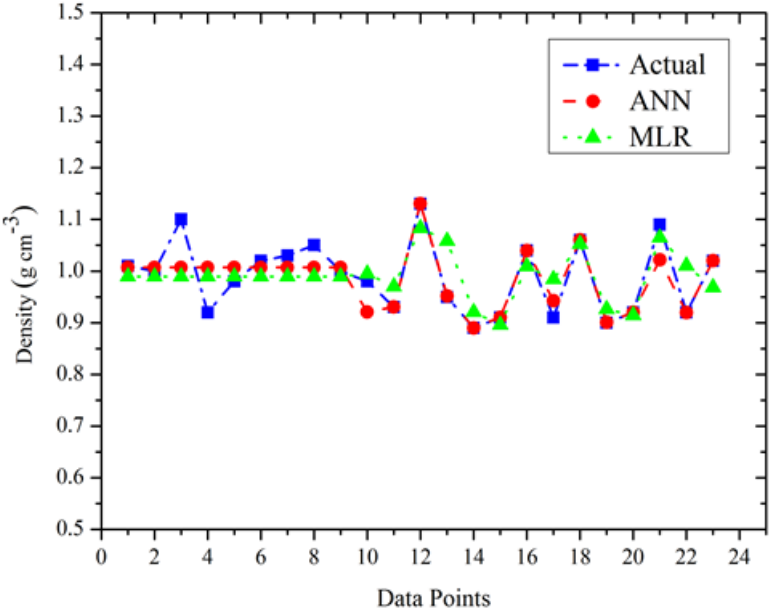

(b)

Figure 4: (a) Plot between predicted (with $\pm 5 \%$ error bar) versus actual density values (b) Plot between actual versus predicted by ANN versus predicted by MLR density values 
Table 3: Coefficients obtained from multiple linear regressions

\begin{tabular}{|c|c|c|c|}
\hline Polynomial Coefficients & Density $(\rho)$ & Durability $(\delta)$ & Impact Resistance $(\eta)$ \\
\hline$m c$ & -0.0186 & -2.7462 & -0.3337 \\
\hline$T$ & 0.0044 & 0.4683 & 0.1001 \\
\hline$P_{a}$ & -0.0012 & -0.1333 & 0.0426 \\
\hline Intercept $\left(\beta_{0}\right)$ & 0.9008 & 76.7641 & 84.5769 \\
\hline
\end{tabular}

The training, validation and testing curve for density prediction is shown in Fig. 5. The polynomial coefficients obtained from MLR is given in Table 3. The effect of three input parameters altogether is not found on the density with much significance, and the only parameter that has a major impact on density here is temperature. The word altogether here tries to convey that all three input variables do not have any linear implications on the output collectively. Input variable(s) may show non-linear behavior depending on the range of values. As the temperature increases, density also increases, which is visible in both experimental and predicted results. It can also be noticed that the increase in the densifying pressure of a specific range increases density. However, when the pressure exceeds a particular value (130 MPa in this case) then the density starts reducing. This phenomenon can be observed in the predicted result as well, with substantial accuracy as shown in Table 1.
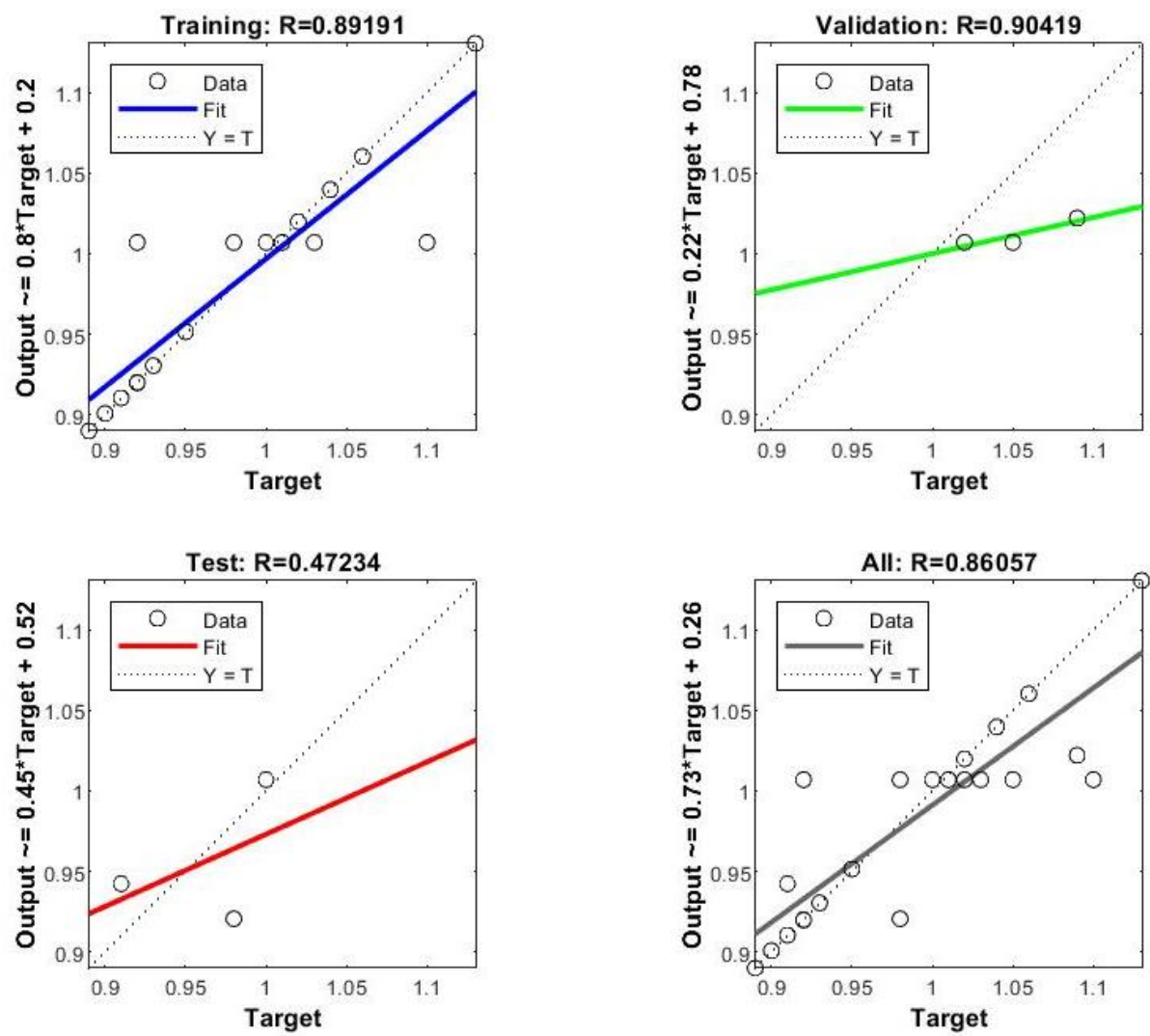

Figure 5: Neural network training, validation and testing curve for density prediction

\subsection{Prediction of Durability $(\delta)$}

The ANN structure, which is used to predict durability with input variables as $m c, T$ and $P_{a}$ is taken in the input layer and durability, $(\delta)$ is taken in the output layer. After training, testing, and validating, it is found that $47.82 \%$ of the data predicted are within the error range of $\pm 5 \%$ as witnessed in Figure $6(\mathrm{a})$. This prediction occurred at epoch 2 with mean square error (MSE) as 0.001134 . The best performance is 
Gaurav Kumar et al., Adv. J. Grad. Res.; Vol. 9, Issue 1, pp: 1-13, January 2021

obtained as epoch 2 because of the occurrence of the lowest value of MSE on the validating sets Figure 10(b). In Fig. 6(b), the comparison between ANN and MLR predictions with actual experimental values is done. It can be seen that the performance of MLR prediction is very poor as it was only able to predict $26.09 \%$ of the data points in the same error range of $\pm 5 \%$, which is nearly half of what ANN predicted. The standard error in this case is 9.38. The polynomial coefficients obtained from MLR is given in Table 3.

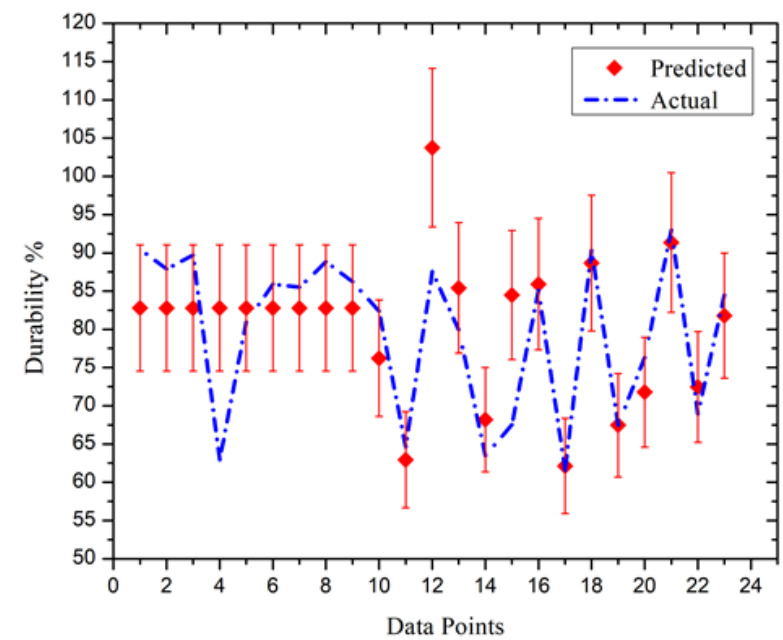

(a)

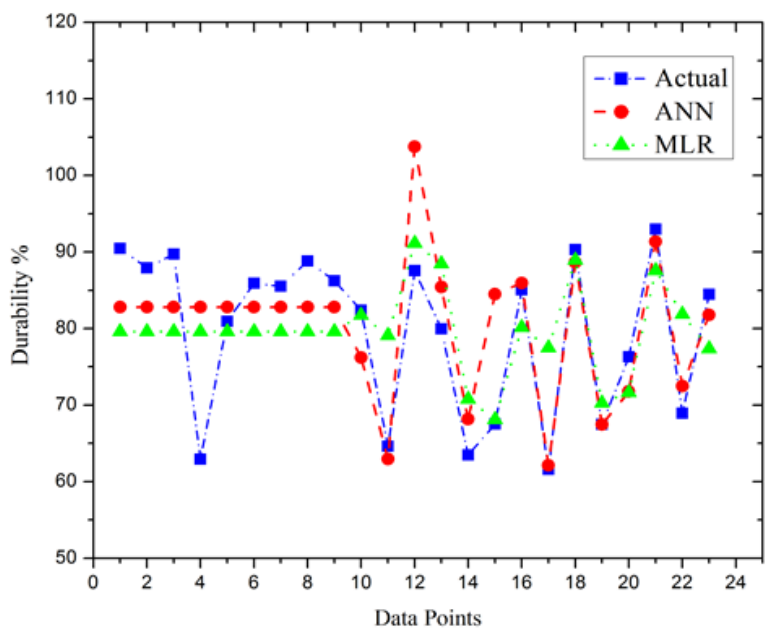

(b)

Figure 6: (a) Plot between predicted (with $\pm 5 \%$ error bar) versus actual durability values (b) Plot between actual versus predicted by ANN versus predicted by MLR durability values

The training, validation and testing curve for durability prediction is shown in Fig. 7. Similar to density $(\rho)$, the effect of the three input parameters altogether is not found on the durability $(\delta)$. However, the influence of the three factors can be stated from both experimental and predicted data as follows: increasing the temperature, decreasing the moisture content, and increasing the pressure, increases the durability.
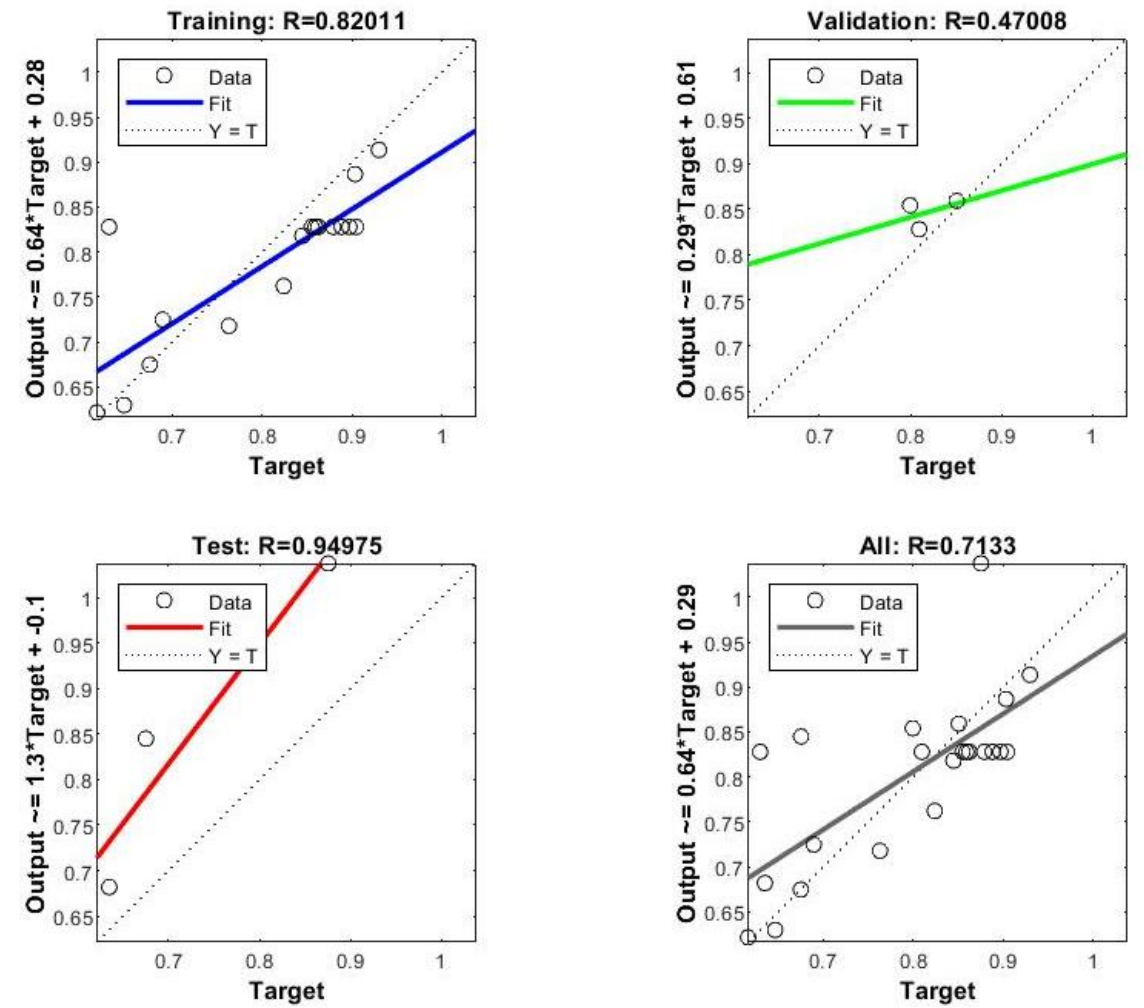

Figure 7: Neural network training, validation and testing curve for durability prediction 


\subsection{Prediction of Impact Resistance $(\eta)$}

The ANN structure (3-10-10-1) also is used with the same input variables $m c, T$ and $P_{a}$ in the input layer, and impact resistance $(\eta)$ is taken in the output layer for the prediction of impact resistance. Quite remarkably, from Fig. 8(a) it is found that, after training, testing, and validating, 100\% of the predicted data are within the error range of $\pm 5 \%$. This prediction occurred at epoch 1 with mean square error (MSE) as 0.00116. The best performance is obtained as epoch 1 because of the occurrence of the lowest value of MSE on the validating sets Figure 10(c). In Fig. 8(b), ANN and MLR prediction is compared with actual experimental values. It can be observed that both ANN and MLR is able to predict data points with high accuracy however in this case too MLR lags behind ANN since only $95.65 \%$ of data points are being predicted by MLR in the error range of $\pm 5 \%$. The standard error is 2.02 . The polynomial coefficients obtained from MLR is given in Table 3. The training, validation and testing curve for impact resistance prediction is shown in Fig. 9. Impact resistance $(\eta)$ also did not get affected by the interaction of three parameters altogether. However, an increase in impact resistance is observed with an increase in temperature within a specific pressure range.

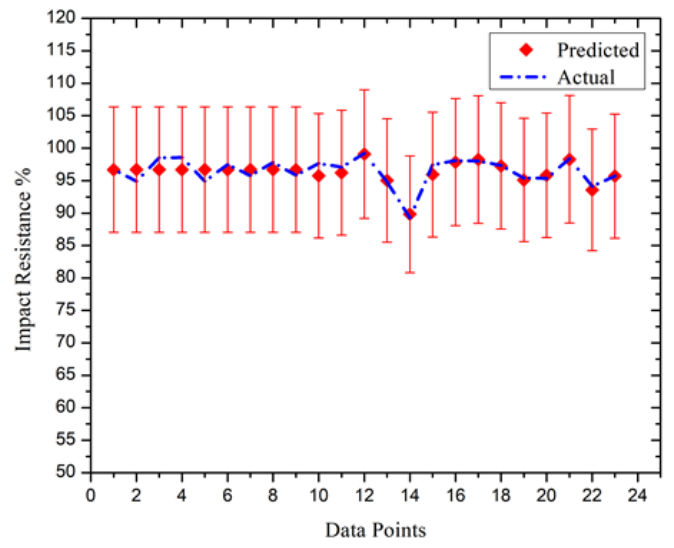

(a)

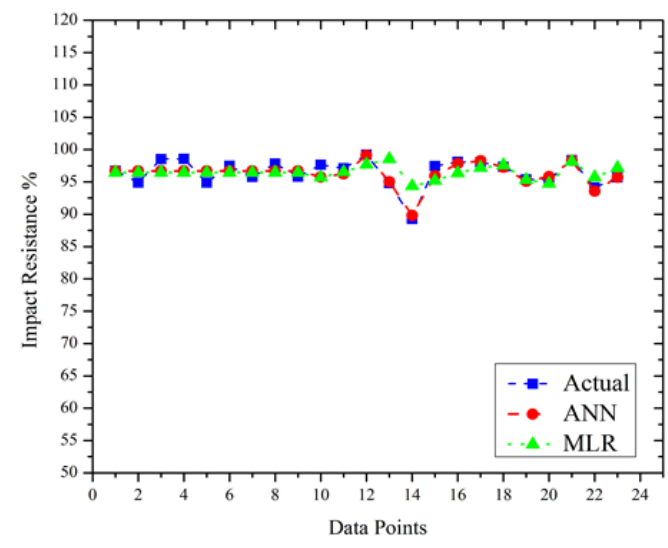

(b)

Figure 8: (a) Plot between predicted (with $\pm 5 \%$ error bar) versus actual impact resistance values (b) Plot between actual versus predicted by ANN versus predicted by MLR impact resistance values
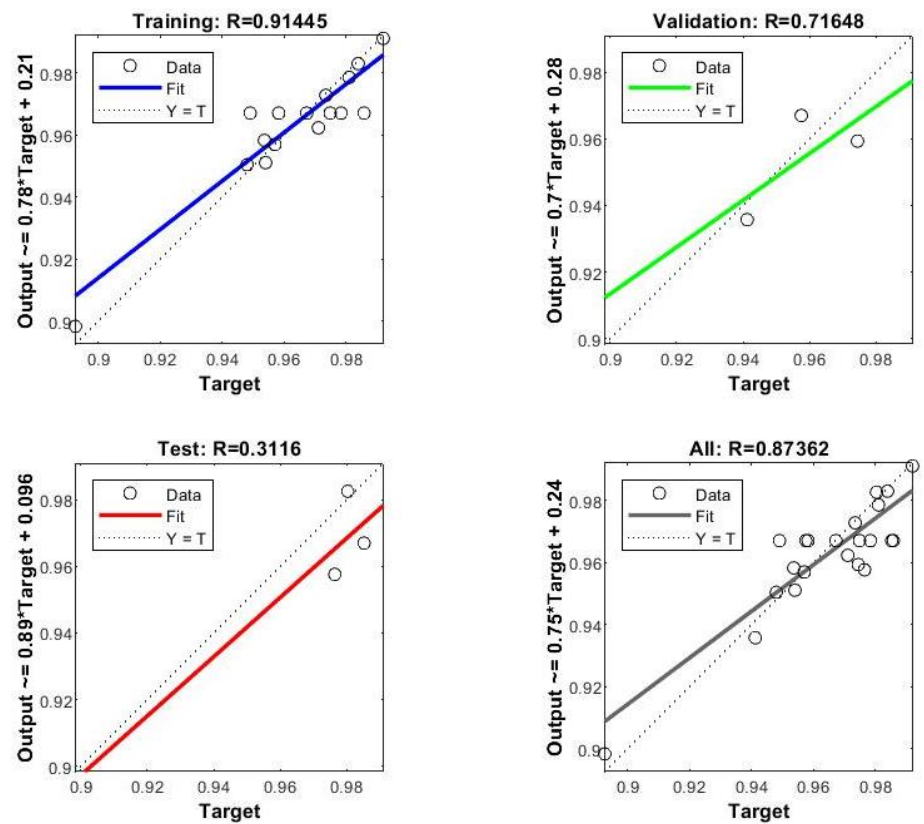

Figure 9: Neural network training, validation and testing curve for impact resistance prediction 
Gaurav Kumar et al., Adv. J. Grad. Res.; Vol. 9, Issue 1, pp: 1-13, January 2021

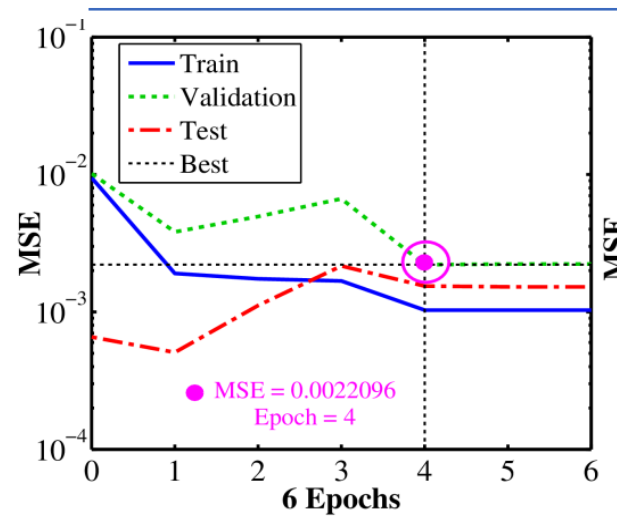

(a)

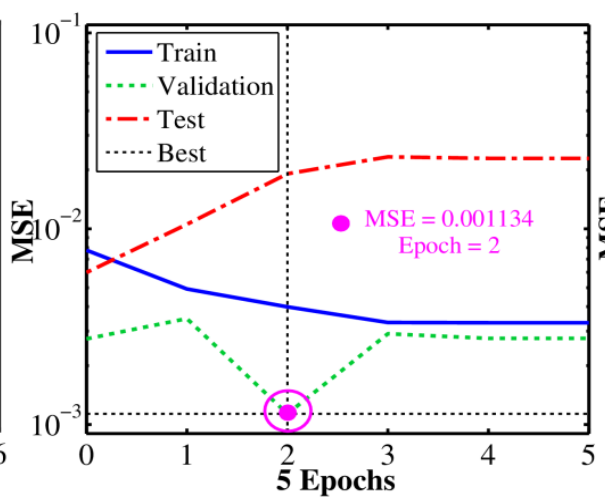

(b)

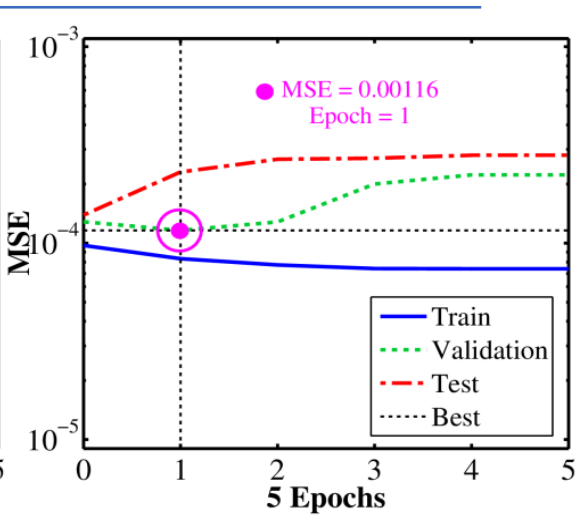

(c)

Figure 10: Best validation performances for (a) Density (b) Durability, and (c) Impact Resistance

All the error values (MSE, MAE, and MBE) are summarized in Table 4. Finally, to validate the performance of the network (3-10-10-1), we present correlation coefficient (regression, R) values for the network outputs in Table 5 concerning the actual outputs (targets) in training, testing, and validation phases. The overall values indicate a good fit as the value of $R$ is closer to 1 . The overall value of $R$ is greater than 0.85 for both density and impact resistance but somewhat lower for durability. This value can be further improved with different ANN models by changing the number of hidden layers and the number of neurons [39]. But to keep uniformity with current analysis and to show how ANN could be useful in predicting any complex relation, the model (3-10-10-1) is constant for predicting all three parameters. Further in Table 6, the comparison of the correlation coefficient values obtained from ANN with MLR is done. It can be easily depicted from the table that ANN can predict all the three parameters more effectively than MLR with higher accuracy.

Table 4: Different error values obtained after ANN modeling for 3-10-10-1 structure

\begin{tabular}{|l|c|c|c|}
\hline & $M S E$ & $M A E$ & $M B E$ \\
\hline Density $(\rho)$ & 0.0022 & 0.02031 & -0.00601 \\
\hline Durability $(\delta)$ & 0.00113 & 5.36386 & 0.72021 \\
\hline Impact Resistance $(\eta)$ & 0.00116 & 0.78939 & -0.18843 \\
\hline
\end{tabular}

Table 5: Correlation coefficient $(R)$ values of the ANN structure in different phases

\begin{tabular}{|l|c|c|c|c|}
\hline & Training & Testing & Validation & Overall \\
\hline Density $(\rho)$ & 0.89191 & 0.47234 & 0.90419 & 0.86057 \\
\hline Durability $(\delta)$ & 0.82011 & 0.94975 & 0.47008 & 0.7133 \\
\hline Impact Resistance $(\eta)$ & 0.91445 & 0.3116 & 0.71648 & 0.87362 \\
\hline
\end{tabular}

Table 6: Correlation coefficient ( $R$ ) values of the ANN versus MLR prediction

\begin{tabular}{|c|c|c|c|c|c|}
\hline \multicolumn{5}{|c|}{$\boldsymbol{R}$ Values } \\
\hline \multicolumn{2}{|c|}{ Density $(\rho)$} & \multicolumn{2}{c|}{ Durability $(\delta)$} & \multicolumn{2}{c|}{ Impact Resistance $(\eta)$} \\
\hline ANN & MLR & ANN & MLR & ANN & MLR \\
\hline 0.861 & 0.668 & 0.713 & 0.554 & 0.874 & 0.474 \\
\hline
\end{tabular}




\section{Conclusions}

In this paper, a multi-layer perceptron neural network trained with back propagation using LevenbergMarquardt (LM) algorithm to predict the performance of the millet bran briquettes has been developed. It is shown that the artificial neural network (ANN) model developed in this study accurately predicts the physical conditions of the briquettes made from millet bran. Furthermore, a double hidden layer ANN structure (3-10-10-1) is used in the prediction for all the three output parameters to maintain linearity with the program. The comparison between actual values (target) and predicted values suggests that the LM algorithm-driven ANN model can establish a relation between input and output events. The value of the correlation coefficient $(R)$ is used to validate this relation. Later, a comparison between ANN and MLR is also incorporated. In case of $A N N$, overall $\mathrm{R}$ values for density, durability, and impact resistance are $0.86057,0.7133$, and 0.87362 respectively, whereas, it is $0.668,0.554$, and 0.474 respectively in case of MLR. From the analysis of the present endeavour, it can be inferred that ANN can be used as a quick and flexible modelling tool with a greater degree accuracy degree for any non-linear problem related to biomass briquettes. The present work is the one of the few attempts in the application of artificial neural networks in this field, and it gives significant motivation to the authors to use ANN in the future works. The use of ANN as an important validation tool (of experimental works) could be considered especially in the field of biomass pellets, briquettes and other related products. It makes the validation quick as well as accurate. Until present investigation, there are not many studies reported in the paradigm of biomass briquette and ANN together, but as seen in the current work, the use of the artificial neural network is the best approach to solve problems where complex relation between parameters are involved.

\section{Declarations}

\subsection{Acknowledgements}

The authors wish to acknowledge the support by the Cochin University Science and Technology, India for providing academic license for MATLAB ${ }^{\circledR}$. Gaurav Kumar acknowledges the support and wishes received from his parents during the work.

\subsection{Competing Interests}

The authors declare that they have no known competing financial interests or personal relationships that could have appeared to influence the work reported in this paper.

\section{How to Cite this Article:}

Gaurav Kumar et al., "Predicting Performance of Briquette Made from Millet Bran: A Neural Network Approach", Adv. J. Grad. Res., vol. 9, no. 1, pp. 1-13, Sep. 2020.

\section{References}

[1] Yank A, Ngadi M, Kok R. Physical properties of rice husk and bran briquettes under low pressure densification for rural applications. Biomass and Bioenergy 2016;84:22-30. https://doi.org/10.1016/j.biombioe.2015.09.015.

[2] Chen L, Xing L, Han L. Renewable energy from agro-residues in China: Solid biofuels and biomass briquetting technology. Renew Sustain Energy Rev 2009;13:2689-95. https://doi.org/10.1016/j.rser.2009.06.025.

[3] Lim JS, Abdul Manan Z, Wan Alwi SR, Hashim H. A review on utilisation of biomass from rice industry as a source of renewable energy. Renew Sustain Energy Rev 2012. https://doi.org/10.1016/j.rser.2012.02.051.

[4] Lubwama M, Yiga VA. Development of groundnut shells and bagasse briquettes as sustainable fuel sources for domestic cooking applications in Uganda. Renew Energy 2017. https://doi.org/10.1016/j.renene.2017.04.041.

[5] Zhang G, Sun Y, Xu Y. Review of briquette binders and briquetting mechanism. Renew Sustain Energy Rev 2018. https://doi.org/10.1016/j.rser.2017.09.072.

[6] Mani S, Tabil LG, Sokhansanj S. Effects of compressive force, particle size and moisture content on mechanical properties of biomass pellets from grasses. Biomass and Bioenergy 2006. https://doi.org/10.1016/j.biombioe.2005.01.004.

[7] Kaliyan N, Vance Morey R. Factors affecting strength and durability of densified biomass products. Biomass and Bioenergy 2009. https://doi.org/10.1016/j.biombioe.2008.08.005.

[8] Zhang J, Zheng D, Wu K, Zhang X. The optimum conditions for preparing briquette made from millet bran using Generalized Distance Function. Renew Energy 2019. https://doi.org/10.1016/j.renene.2019.03.079.

[9] Kumar A, Kumar N, Baredar P, Shukla A. A review on biomass energy resources, potential, conversion and policy in India. Renew Sustain Energy Rev 2015. https://doi.org/10.1016/j.rser.2015.02.007. 
Gaurav Kumar et al., Adv. J. Grad. Res.; Vol. 9, Issue 1, pp: 1-13, January 2021

[10] Muazu RI, Stegemann JA. Effects of operating variables on durability of fuel briquettes from rice husks and corn cobs. Fuel Process Technol 2015. https://doi.org/10.1016/j.fuproc.2015.01.022.

[11] Lee S min, Ahn BJ, Choi DH, Han GS, Jeong HS, Ahn SH, et al. Effects of densification variables on the durability of wood pellets fabricated with Larix kaem $p$ feri C. and Liriodendron tulipifera L. sawdust. Biomass and Bioenergy 2013. https://doi.org/10.1016/j.biombioe.2012.10.015.

[12] Demirbaş A. Physical properties of briquettes from waste paper and wheat straw mixtures. Energy Convers Manag 1999. https://doi.org/10.1016/S0196-8904(98)00111-3.

[13] Yaman S, Şahan M, Haykiri-Açma H, Şeşen K, Küçükbayrak S. Fuel briquettes from biomass-lignite blends. Fuel Process Technol 2001. https://doi.org/10.1016/S0378-3820(01)00170-9.

[14] Panwar V, Prasad B, Wasewar KL. Biomass residue briquetting and characterization. J Energy Eng 2011. https://doi.org/10.1061/(ASCE)EY.1943-7897.0000040

[15] Tian Z, Qian C, Gu B, Yang L, Liu F. Electric vehicle air conditioning system performance prediction based on artificial neural network. Appl Therm Eng 2015. https://doi.org/10.1016/j.applthermaleng.2015.06.002.

[16] Benli H. Determination of thermal performance calculation of two different types solar air collectors with the use of artificial neural networks. Int J Heat Mass Transf 2013. https://doi.org/10.1016/j.ijheatmasstransfer.2012.12.042.

[17] Basheer IA, Hajmeer M. Artificial neural networks: Fundamentals, computing, design, and application. J Microbiol Methods 2000. https://doi.org/10.1016/S0167-7012(00)00201-3.

[18] Russell SJ, Norvig P. Artificial Intelligence: A Modern ApproachRussell, S. J., \& Norvig, P. (2010). Artificial Intelligence: A Modern Approach. Artificial Intelligence. https://doi.org/10.1017/S0269888900007724. 2010. https://doi.org/10.1017/S0269888900007724.

[19] Abiodun OI, Jantan A, Omolara AE, Dada KV, Mohamed NAE, Arshad H. State-of-the-art in artificial neural network applications: A survey. Heliyon 2018. https://doi.org/10.1016/j.heliyon.2018.e00938.

[20] Mohanraj M, Jayaraj S, Muraleedharan C. Applications of artificial neural networks for thermal analysis of heat exchangers - A review. Int J Therm Sci 2015. https://doi.org/10.1016/j.ijthermalsci.2014.11.030.

[21] Kalogirou SA. Artificial neural networks in renewable energy systems applications: A review. Renew Sustain Energy Rev 2000. https://doi.org/10.1016/S1364-0321(01)00006-5.

[22] Jensen RR, Karki S, Salehfar H. Artificial neural network-based estimation of mercury speciation in combustion flue gases. Fuel Process. Technol., 2004. https://doi.org/10.1016/j.fuproc.2003.11.020.

[23] Haykin S. Neural networks: a comprehensive foundation by Simon Haykin. Knowl Eng Rev 1999. https://doi.org/10.1017/S0269888998214044.

[24] Esen H, Inalli M, Sengur A, Esen M. Forecasting of a ground-coupled heat pump performance using neural networks with statistical data weighting pre-processing. Int J Therm Sci 2008. https://doi.org/10.1016/j.jthermalsci.2007.03.004.

[25] Caner M, Gedik E, Keĉebas A. Investigation on thermal performance calculation of two type solar air collectors using artificial neural network. Expert Syst Appl 2011. https://doi.org/10.1016/j.eswa.2010.07.090.

[26] Duchesne MA, MacChi A, Lu DY, Hughes RW, McCalden D, Anthony EJ. Artificial neural network model to predict slag viscosity over a broad range of temperatures and slag compositions. Fuel Process. Technol., 2010. https://doi.org/10.1016/j.fuproc.2009.10.013.

[27] Liu Y, Wang H, Zhang H, Liber K. A comprehensive support vector machine-based classification model for soil quality assessment. Soil Tillage Res 2016. https://doi.org/10.1016/j.still.2015.07.006.

[28] Tan P, Zhang C, Xia J, Fang QY, Chen G. Estimation of higher heating value of coal based on proximate analysis using support vector regression. Fuel Process Technol 2015. https://doi.org/10.1016/j.fuproc.2015.06.013.

[29] Gong S, Sasanipour J, Shayesteh MR, Eslami M, Baghban A. Radial basis function artificial neural network model to estimate higher heating value of solid wastes. Energy Sources, Part A Recover Util Environ Eff 2017. https://doi.org/10.1080/15567036.2017.1370513.

[30] Abbasi M, Rastgoo MN, Nakisa B. Monthly and seasonal modeling of municipal waste generation using radial basis function neural network. Environ Prog Sustain Energy 2019. https://doi.org/10.1002/ep.13033.

[31] Panchal F, Panchal M. Optimizing Number of Hidden Nodes for Artificial Neural Network using Competitive Learning Approach. 2015.

[32] Akkaya E. ANFIS based prediction model for biomass heating value using proximate analysis components. Fuel 2016. https://doi.org/10.1016/j.fuel.2016.04.112.

[33] Obafemi O, Stephen A, Ajayi O, Nkosinathi M. A survey of artificial neural network-based prediction models for thermal properties of biomass. Procedia Manuf., 2019. https://doi.org/10.1016/j.promfg.2019.04.103.

[34] Stinchcombe M, White H. Universal approximation using feedforward networks with non-sigmoid hidden layer activation functions, 1989. https://doi.org/10.1109/ijenn.1989.118640.

[35] Cybenko G. Approximation by superpositions of a sigmoidal function. Math Control Signals, Syst 1989;2:303-14. https://doi.org/10.1007/BF02551274.

[36] Sayin C, Ertunc HM, Hosoz M, Kilicaslan I, Canakci M. Performance and exhaust emissions of a gasoline engine using artificial neural network. Appl Therm Eng 2007. https://doi.org/10.1016/j.applthermaleng.2006.05.016.

[37] Özgören YÖ, Çetinkaya S, Saridemir S, Çiçek A, Kara F. Predictive modeling of performance of a helium charged Stirling engine using an artificial neural network. Energy Convers Manag 2013. https://doi.org/10.1016/j.enconman.2012.12.007.

[38] Zheng X, Jiang Z, Ying Z, Song J, Chen W, Wang B. Role of feedstock properties and hydrothermal carbonization conditions on fuel properties of sewage sludge-derived hydrochar using multiple linear regression technique. Fuel 2020. https://doi.org/10.1016/j.fuel.2020.117609.

[39] Sheela KG, Deepa SN. Review on methods to fix number of hidden neurons in neural networks. Math Probl Eng 2013. https://doi.org/10.1155/2013/425740

Publish your books with AIJR publisher-

* Publish with ISBN and DOI.

* Publish Thesis/Dissertation as Monograph.

* Publish Book Monograph.

* Publish Edited Volume/ Book.

* Publish Conference Proceedings

* Retain full copyright of your books.

Submit your manuscript at books.aijr.org
Publish your research article in AIJR journals-

* Online Submission and Tracking

* Peer-Reviewed

* Rapid decision

* Immediate Publication after acceptance

* Articles freely available online

* Retain full copyright of your article.

Submit your article at journals.aijr.in 